\title{
QCAL-a Novel Standard for Assessing Instrument Conditions for Proteome Analysis
}

\author{
Claire E. Eyers, ${ }^{a}$ Deborah M. Simpson, ${ }^{b}$ Stephen C. C. Wong, ${ }^{a}$ \\ Robert J. Beynon, ${ }^{\mathrm{b}}$ and Simon J. Gaskell ${ }^{\mathrm{a}}$ \\ ${ }^{a}$ Michael Barber Centre for Mass Spectrometry, Manchester Interdisciplinary Biocentre, School of Chemistry, \\ University of Manchester, Manchester, United Kingdom \\ ${ }^{b}$ Protein and Functional Genomics Group, Department of Veterinary Preclinical Sciences, Faculty of \\ Veterinary Sciences, University of Liverpool, Liverpool, United Kingdom
}

If proteome datasets are to be collated, shared, and merged for higher level proteome analyses, there is a need for generally accepted strategies and reagents for optimization and standardization of instrument performance. At present, there is no single protein or peptide standard set that is capable of assessing instrument performance for peptide separation and analysis in this manner. To create such a standard, we have used the recently described QconCAT methodology to generate an artificial protein, QCAL. This protein, a concatenation of tryptic peptides that is expressed in E. coli, provides a stoichiometrically controlled mixture of peptides that are amenable to analysis by all commonly used instrumentation platforms for proteomics. (J Am Soc Mass Spectrom 2008, 19, 1275-1280) (C 2008 American Society for Mass Spectrometry

$\mathrm{T}$ The preferred method of peptide characterization is reversed-phase chromatography combined with mass spectrometric analysis. The wide range of chromatographic platforms, mass spectrometers, and data analysis packages make comparison between different instruments challenging. Yet, as we move towards common data standards for publication and archiving of proteomics data, there is an increasing need to normalize such datasets with a common analytical control to permit their meaningful comparison and aggregation. Currently, proteomics researchers use diverse criteria for instrument calibration and optimization. Indeed, many laboratories using multiple mass spectrometers use different standards, often defined by the manufacturer, for calibration and optimization of their individual instruments. In addition, the experimental conditions (solvents, solid-phase, and elution gradient) used for pre-analytical peptide separation are seldom consistent. This makes both intra- and interlaboratory comparisons of proteomics data almost impossible to perform with any degree of consistency, as is often apparent with the analyses performed by multiple facilities through the Association of Biomolecular Resource Facility (ABRF) (http://www.abrf.org/index. $\mathrm{cfm} /$ group.show/Proteomics.34.htm) studies. Increasingly, there is also concern about specifically defining how proteomics datasets are generated [1], and this will include the analytical capability of the instrument used.

Normalization of these systems could be achieved

Address reprint requests to Professor S. J. Gaskell, Michael Barber Centre for Mass Spectrometry, The University of Manchester, Manchester Interdisciplinary Biocentre, The John Garside Building, 131 Princess Street, Manchester, M1 7DN, UK. E-mail: Simon.Gaskell@manchester.ac.uk with a universal standard, chosen to assess all aspects of performance and provide a reference analysis that can be fully recorded. Moreover, as experience grows with such a standard, it would be possible to use the behavior of such material as a quality control driver, setting minimal standards for chromatographic resolution, ion selection, fragmentation, and sensitivity. No single protein has yet been characterized that fulfils these requirements. We have recently demonstrated that designer proteins can be used to create a concatenation of tryptic peptides that are surrogate internal standards for absolute protein quantification (QconCAT), [2-4]. However, there are many other feasible applications of designer proteins that can permit exploration of peptide behavior in proteomics and mass spectrometry. Additionally, the low cost and ease of production of the designer protein product makes this preferable to individually synthesizing peptides. Here, we describe the design and analysis of an artificial polypeptide (QCAL1) to optimize and define instrument conditions for peptide analysis by mass spectrometry, whether preceded or not by reversed-phase chromatography.

\section{Experimental \\ QCAL Construction}

The peptide sequences of interest were concatenated in silico and used to direct the design of a gene, codonoptimized for expression in E. coli. Additional sequences were added to provide an initiator methionine residue (MGALR) and $\mathrm{a} \mathrm{His}_{6}$ sequence (ALVALVHHHHHH) for affinity purification using Ni-NTA resin. The gene was 
synthesized and cloned into the expression vector $\mathrm{pET} 21 \mathrm{a}$ by PolyQuant GmbH (http://www.polyquant.com/).

\section{QCAL Expression and Sample Preparation}

QCAL was expressed in E. coli BL21 (DE3) cells and purified on a Ni-NTA column as previously described [3], diluted to $1 \mathrm{mg} / \mathrm{mL}$ in $50 \mathrm{mM} \mathrm{NH} \mathrm{HCO}_{3}$ and digested with $2 \%(\mathrm{wt} / \mathrm{wt})$ trypsin, overnight at $37^{\circ} \mathrm{C}$. Digested QCAL (1 nmol) was dried by vacuum centrifugation and, for some analyses, guanidination of lysine residues was performed by addition of $\mathrm{NH}_{4} \mathrm{OH}(7 \mathrm{M}, 10$ $\mu \mathrm{L})$ and O-methylisourea (0.5 $\mathrm{M}$ in water, $5 \mu \mathrm{L})$. After overnight incubation, samples were desalted using $\mathrm{C}_{18}$ ZipTips (Millipore, Watford, UK) before MALDI-TOF analysis.

\section{Nanoflow LC-MS Analysis}

QCAL was reduced with DTT $\left(10 \mathrm{mM}, 56^{\circ} \mathrm{C}\right.$ for $\left.1 \mathrm{~h}\right)$ and alkylated (55 $\mathrm{mM}$ iodoacetamide, room temperature, dark, $45 \mathrm{~min}$ ) and the protein precipitated with trichloroacetic acid before reconstitution in $50 \mathrm{mM}$ $\mathrm{NH}_{4} \mathrm{HCO}_{3}$ and digestion. Tryptic peptides (500 fmol) were desalted in-line using a $5 \mathrm{~mm} \times 300 \mu \mathrm{m} \mathrm{C18}$ precolumn, before separation by reversed-phase chromatography with a PepMap C18 column ( $3 \mu \mathrm{m}, 0.075 \times$ $150 \mathrm{~mm}, 100 \AA$ ) , both from LC Packings Dionex (Surrey, UK). Chromatography was performed at $200 \mathrm{~nL} / \mathrm{min}$ using an EASY-nLC (Proxeon, Odense, Denmark) nanoflow system arranged in-line with a QTOF micro (Waters, Milford, MA). The column was equilibrated in $0.2 \%$ formic acid (Solvent A) and was developed with $90 \%$ acetonitrile/ $0.2 \%$ formic acid (Solvent B); $0 \%$ to $20 \%$ over $30 \mathrm{~min}, 20 \%$ to $60 \%$ over $10 \mathrm{~min}$, and $60 \%$ to $100 \%$ over $5 \mathrm{~min}$.

\section{Matrix-Assisted Laser-Desorption Ionization-Time of Flight (MALDI-TOF) Mass Spectrometry}

MALDI-TOF MS analysis was performed using either the Voyager-DE STR (Applied Biosystems, Foster City, CA) or the Ultraflex II TOF/TOF (Bruker Daltonics, Bremen, Germany) with digested QCAL crystallized with a saturated solution of $\alpha$-cyano-4-hydroxycinnamic acid in 50\% (vol/vol) acetonitrile, $0.1 \%$ (vol/vol) trifluoroacetic acid. Detection was performed in reflector mode with delayed extraction.

\section{Fourier Transform Ion Cyclotron Resonance (FT ICR) Mass Spectrometry}

Digested QCAL was desalted using a $C_{18}$ peptide trap (Michrom Bioresources, Auburn, CA), dried by vacuum centrifugation and resuspended in 50\% (vol/vol) acetonitrile, $0.1 \%$ (vol/vol) formic acid to $1 \mathrm{pmol} / \mu \mathrm{L}$. Peptides were infused and analyzed using a Bruker Daltonics Apex III 9.4T FT ICR mass spectrometer (Billerica,
MA) and an electrospray source. Data acquisition was performed with the Bruker Xmass software, version 6.01 (Bruker Daltonics, Bremen, Germany). Mass spectra were collected using $512 \mathrm{~K}$ data points per scan, over a range of $m / z$ 50-5000. High-resolution data were collected over a range of $\mathrm{m} / \mathrm{z} 650-1500$.

\section{Results and Discussion}

QCAL1, an artificial protein constructed using the QconCAT methodology [2-4], is a concatenation of 22 unique tryptic peptide sequences (Table 1) designed for the calibration, optimization, and comparison of a range of mass spectrometers. The QCAL1 peptides were additionally designed to assess and optimize instrument resolution, test the linearity of signal detection, and evaluate peptide separation by reversed-phase chromatography. As these peptides are incorporated into an artificial protein, it is also necessary for the user to validate common sample preparation procedures such as tryptic digestion and desalting. Characteristics are also incorporated within the design to assess peptide modification such as deamidation, methionine oxidation, and modification of lysine residues.

Peptide mass fingerprinting (PMF) experiments are typically performed using a matrix-assisted laserdesorption ionization (MALDI) time-of-flight (TOF) mass spectrometer for the identification of proteins following in-gel digestion with trypsin [5]. The peptides that are generated under these conditions and subsequently used for database searching, typically range between 500 and 3500 Da. However, MALDI-TOF instruments are usually calibrated with a mixture of synthetic peptides $\geq 900 \mathrm{Da}$, even though smaller peptides may enhance search algorithm scores and improve protein identification. QCAL1 was therefore designed to generate tryptic peptides with $[\mathrm{M}+\mathrm{H}]^{+} \mathrm{m} / z$ values between $\sim 400$ and 3000. MALDI-TOF mass spectrometry of digested QCAL1 using a Voyager-DE STR (Figure 1a) demonstrates that up to $19[\mathrm{M}+\mathrm{H}]^{+}$ peptide ions can be used for calibration over the $\mathrm{m} / \mathrm{z}$ range 400 to 3200 . Similar data were also observed following MALDI analysis with an Ultraflex II TOF/ TOF.

In MALDI-TOF MS, arginine-terminated tryptic peptides often give superior signals to their lysineterminating counterparts [6]; however, peptide signals can be enhanced by conversion of lysine residues to homoarginine [7-9]. The almost identical peptides 8 and 11 (Table 1) were thus incorporated to test the efficiency of C-terminal homoarginine formation by lysine guanidination. MALDI-TOF spectra over $\mathrm{m} / \mathrm{z}$ range 1410-1490, before (Figure 1b) and after (Figure 1c) guanidination are depicted, clearly indicating preferential detection of the lysine-terminating Q11 peptide after modification $\left(\mathrm{Q} 11^{*}\right)$. Based on the change in isotope distribution post-guanidination, base catalyzed deamidation of the peptides can also be observed [10]. 
Table 1. Sequence and function of QCAL1 peptides

\begin{tabular}{|c|c|c|c|c|c|c|c|}
\hline $\begin{array}{c}\text { Q- } \\
\text { peptide }\end{array}$ & Sequence & Primary function & $\begin{array}{c}{[\mathrm{M}+\mathrm{H}]^{+}:} \\
\mathrm{m} / \mathrm{z}\end{array}$ & $\begin{array}{c}{[\mathrm{M}+2 \mathrm{H}]^{2+}:} \\
\mathrm{m} / \mathrm{z}\end{array}$ & $\begin{array}{c}\text { Relative } \\
\psi\end{array}$ & $\begin{array}{l}\text { Predicted } \\
\text { retention } \\
\text { time (min) }\end{array}$ & $\begin{array}{c}\text { Actual } \\
\text { retention } \\
\text { time (min) }\end{array}$ \\
\hline 1 & VFDEFKPLVEEPONLIR & $m / z, L C$ & 2073.1015 & 1037.0544 & 35.98 & 40.0 & 39.3 \\
\hline 2 & VFDEFKPLVKPEEPQNLIR & $\mathrm{m} / \mathrm{z}$, resolution, $\mathrm{LC}$ & 2298.2492 & 1149.6283 & 34.51 & 39.3 & 37.9 \\
\hline 3 & VFDEFKPLVKPEEKPONLIR & $m / z$, resolution, LC & 2426.3442 & 1213.6757 & 32.52 & 38.3 & 34.6 \\
\hline 4 & VFDEFKPLVKPEEKPONKPLIR & $\mathrm{m} / \mathrm{z}$, resolution, LC & 2651.4919 & 1326.2496 & 30.39 & 37.2 & 31.1 \\
\hline 5 & VFKPDEFKPLVKPEEKPONKPLIR & $m / z$, resolution, LC & 2876.6397 & 1438.8235 & 28.23 & 36.1 & 29.6 \\
\hline 6 & VFKPDEFKPLVKPEEKPQNKPLIKPR & $m / z$, resolution, LC & 3101.7874 & 1551.3973 & 26.66 & 35.3 & 28.4 \\
\hline 7 & VFDEFOPLVEEPQNLIR & resolution (Q1) & 2073.0651 & 1037.0368 & 37.90 & 41.0 & 40.1 \\
\hline 8 & GVNDNEEGFFSAR & calibration, linearity & 1441.6342 & 721.3208 & 22.50 & 33.2 & 34.0 \\
\hline 9 & {$[G G V N D N E E G F F S A R]_{3}^{a}$} & linearity of response & 1498.6557 & 749.8315 & 23.20 & 33.6 & 33.8 \\
\hline 10 & 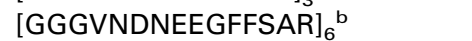 & linearity of response & 1555.6772 & 778.3422 & 22.92 & 33.5 & 33.7 \\
\hline \multirow[t]{2}{*}{11} & GVNDNEEGFFSAK & guanidination (08) & 1413.6281 & 707.3177 & 21.97 & 33.0 & 33.1 \\
\hline & GVNDNEEGFFSA[Har] & guanidination $(\mathrm{Q} 8)$ & 1455.6499 & 728.3286 & - & - & - \\
\hline 12 & AVMDDFAAFVEK & Met ox., LC & 1342.6354 & 671.8216 & 36.14 & 40.1 & 39.8 \\
\hline 13 & AVMMDDFAAFVEK & Met ox., LC & 1473.6758 & 737.3419 & 38.14 & 41.1 & 40.1 \\
\hline 14 & AVMMMDDFAAFVEK & Met ox., LC & 1604.7163 & 802.8621 & 40.94 & 42.5 & 40.5 \\
\hline 15 & GLVK & $m / z$ & 416.2873 & 208.6476 & 10.07 & 27.0 & N.D. \\
\hline 16 & FVVPR & $m / z, L C$ & 617.3776 & 309.1927 & 16.98 & 30.5 & 30.9 \\
\hline 17 & ALELFR & $m / z, L C$ & 748.4358 & 374.7218 & 28.17 & 36.1 & 34.7 \\
\hline 18 & IGDYAGIK & $m / z, L C$ & 836.4518 & 418.7299 & 17.27 & 30.6 & 27.1 \\
\hline 19 & EALDFFAR & $m / z, L C$ & 968.4842 & 484.7460 & 31.77 & 37.9 & 38.7 \\
\hline 20 & YLGYLEQLLR & $m / z, L C$ & 1267.7051 & 634.3565 & 38.27 & 41.1 & 40.4 \\
\hline 21 & VLYPNDNFFEGK & $m / z, L C$ & 1442.6957 & 721.8518 & 29.19 & 36.6 & 38.3 \\
\hline \multirow[t]{2}{*}{22} & LFTFHADICTLPDTEK & $\mathrm{m} / \mathrm{z}$, LC, Cys alkylation & 1850.8999 & 925.9539 & 31.68 & 37.8 & N.D. \\
\hline & LFTFHADIC*TLPDTEK & $\mathrm{m} / \mathrm{z}$, LC, Cys alkylation & 1907.9208 & 954.4640 & - & - & 38.4 \\
\hline
\end{tabular}

Listed for each peptide is the sequence, primary reason for inclusion in OCAL 1 , the monoisotopic $\mathrm{m} / \mathrm{z}$ ratio of the singly and doubly protonated peptide, the relative hydrophobicity $(\psi)$ and retention time as predicted using the sequence-specific retention calculator algorithm [16] (http:// hs2.proteome.ca/SSRCalc/SSRCalc.html), together with the actual retention time following reversed-phase chromatography. Each peptide is present as single copy except ${ }^{\mathrm{a}} \mathrm{Q} 9$ with 3 copies and ${ }^{\mathrm{b}} \mathrm{Q} 10$ with 6 copies. [Har] represents homoarginine. $\mathrm{C}^{*}$ represents carbamidomethyl cysteine. N.D.: not detected.

Q21, previously overlapping with Q8, can also be clearly observed post-guanidination.

High-resolution Fourier Transform mass spectrometers, such as the ion cyclotron resonance (FT ICR) and Orbitrap instruments allow the determination of analyte masses to high accuracy (low or sub-ppm). Increasing use is therefore being made of these instruments in proteomics applications, primarily due to the reduction in false positive automated peptide identifications [11, 12]. Calibration of these instruments can be achieved using QCAL1 either as an external calibrant (Figure 2) (where average mass accuracy sub- 1 ppm was achieved using the ICR instrument) or as an internal calibrant. To assess the resolving power of instruments such as these, QCAL1 incorporates peptides Q1 and Q7, representing a lysine to glutamine substitution, a difference of $0.0364 \mathrm{Da}$. Discriminating these two peptides requires an instrument resolution of $\geq 57,000$ (FWHM), quite within the capabilities of both the instruments mentioned above. Data acquired on a 9.4T FT ICR mass spectrometer indicate that, as expected, these two peptides can be readily distinguished (Figure $2 \mathrm{c}$ ), with peak resolution $>105,000$ (FWHM) being observed. Differentiation of these peptides can therefore be used as a benchmark for instrument resolution. In addition, deamidation of a number of tryptic peptides from QCAL1 was observed, with the amount of deamidation being dependent on sample preparation. The extent of deamidation can be adjusted by exposure of the peptides, rather than QCAL1, to high $\mathrm{pH}$ [13]. Detection of the deamidated form of $\mathrm{Q}^{2+}$ (and its discrimination relative to the native $Q 9^{2+}$ first $\left[{ }^{13} \mathrm{C}\right]$ isotopomer peak) (Figure $2 \mathrm{~b}$ ) requires an instrument resolution $>94,000$ and can thus be used as an additional specification for standardizing the performance of high-resolution instruments.

Methionine oxidation is often observed as an artifact during sample preparation and it is thus difficult to discriminate artificially induced oxidation from posttranslationally modified methionine. Peptides Q12, Q13, and Q14 were thus included to assess methionine oxidation as a result of sample handling. MALDI-TOF analysis of performic acid-induced oxidation of QCAL1 tryptic peptides demonstrated methionine sulfone formation on all three methionine containing peptides (data not shown), validating utility of these peptides to assess in vitro methionine oxidation.

Critical to the success of proteomics experiments and the characterization of peptides within complex mixtures is their separation by reversed-phase chromatography before mass spectrometric analysis. QCAL1 was therefore designed to incorporate peptides with a range of hydrophobicities, thereby permitting evaluation of reversed-phase chromatographic conditions for peptide separation. QCAL1 peptides demonstrated good chromatographic reso- 


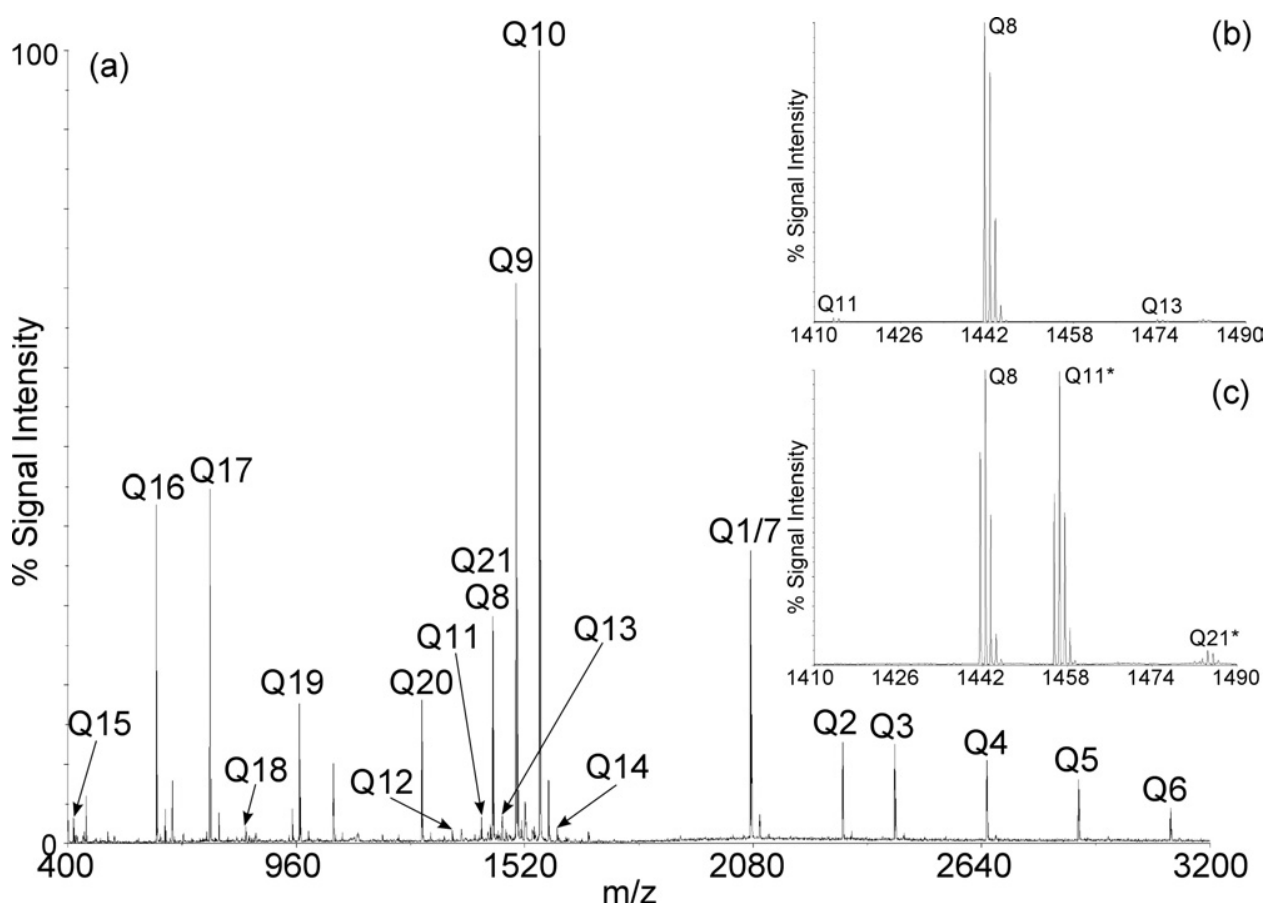

Figure 1. MALDI-TOF mass spectra of digested QCAL1. Limit peptides (the products of complete hydrolysis by the protease) generated after tryptic digestion of QCAL1 were analyzed following MALDI using a Voyager DE STR (a). Inset: trypsin hydrolysate of QCAL1 analyzed before guanidination (b) fails to differentiate Q8 and Q21. After guanidination (c) these peptides are clearly identifiable. Signal intensity of Q11 is also dramatically improved postguanidination.

lution, eluting between $5 \%$ and $\sim 35 \%$ acetonitrile (Table 1, Figure 3), the typical range over which most tryptic peptides elute from $\mathrm{C}_{18}$ media $[14,15]$.
A significant number of laboratories use the $\left[\mathrm{Glu}^{1}\right]-$ fibrinopeptide B ("Glufib"; EGVNDNEEGFFSAR) to assess instrument sensitivity, and for calibration of

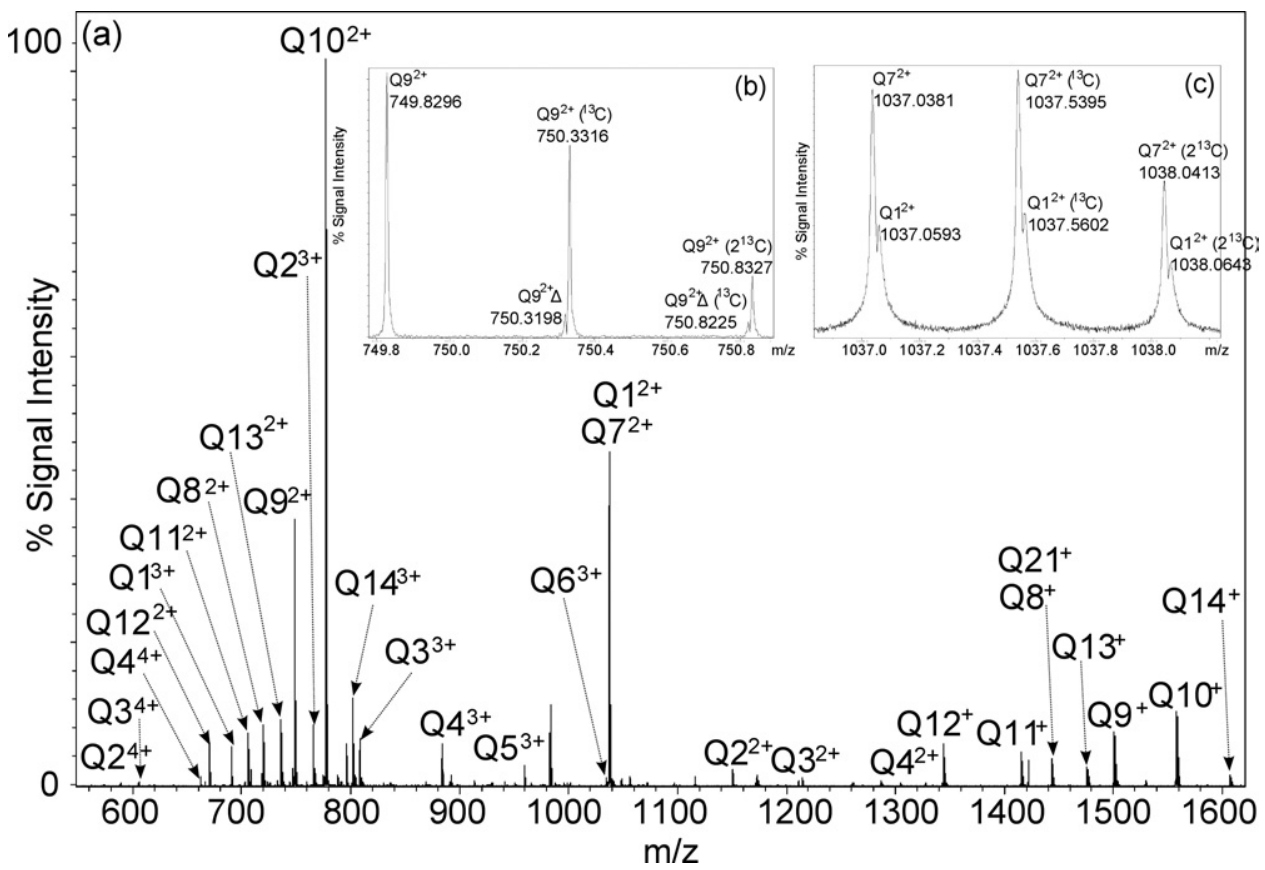

Figure 2. ESI FT ICR mass spectra of digested QCAL1 (a). Insets (b), (c) are high-resolution mass spectra collected over a range of $m / z 650-1500$, confirming that the resolution in this instrument mode is sufficient to readily detect peptide deamidation (b). In this case deamidated Q9 (Q9 $\Delta)$ is depicted. The doubly charged species of Q1 and Q7, separated by 0.0182 Th can also be readily differentiated (c). 


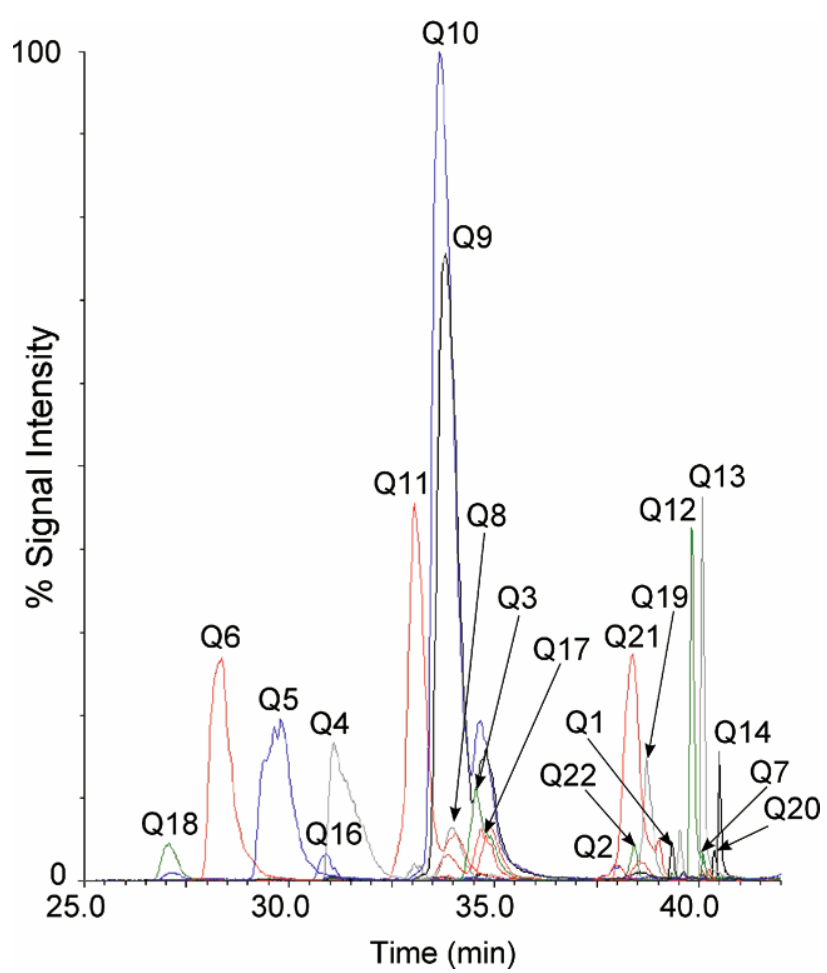

Figure 3. Analysis of digested QCAL1 by LC-MS/MS. Overlaid are the extracted ion chromatograms for the singly protonated species of Q16 (m/z of 617.4; peak at $30.9 \mathrm{~min})$, Q17 $(\mathrm{m} / \mathrm{z}$ of 748.4; peak at $34.7 \mathrm{~min})$; doubly protonated species of Q7 $(\mathrm{m} / \mathrm{z}$ of 1037.0 ; peak at $40.1 \mathrm{~min}), \mathrm{Q} 8(\mathrm{~m} / \mathrm{z}$ of 721.3 ; peak at $34.0 \mathrm{~min}), \mathrm{Q} 9(\mathrm{~m} / \mathrm{z}$ of 749.8; peak at $33.8 \mathrm{~min}), \mathrm{Q} 10(\mathrm{~m} / \mathrm{z}$ of 778.3; peak at $33.7 \mathrm{~min}), \mathrm{Q} 11$ $(\mathrm{m} / \mathrm{z}$ of 707.3 ; peak at $33.1 \mathrm{~min}), \mathrm{Q} 12(\mathrm{~m} / \mathrm{z}$ of 671.8 ; peak at 39.8 $\mathrm{min}), \mathrm{Q} 13(\mathrm{~m} / \mathrm{z}$ of 737.34; peak at $40.1 \mathrm{~min}), \mathrm{Q} 14(\mathrm{~m} / \mathrm{z}$ of 802.9; peak at $40.5 \mathrm{~min}), \mathrm{Q} 18(\mathrm{~m} / \mathrm{z}$ of 418.7 ; peak at $27.1 \mathrm{~min}), \mathrm{Q} 19(\mathrm{~m} / \mathrm{z}$ of 484.7 ; peak at $38.7 \mathrm{~min}), \mathrm{Q} 20(\mathrm{~m} / \mathrm{z}$ of 634.4 ; peak at $40.4 \mathrm{~min}), \mathrm{Q} 21(\mathrm{~m} / \mathrm{z}$ of 721.9; peak at $38.3 \mathrm{~min})$; triply protonated species of Q1 $(\mathrm{m} / \mathrm{z}$ of 691.7; peak at $39.3 \mathrm{~min})$; quadruply charged species of Q2 $(\mathrm{m} / \mathrm{z}$ of 575.3; peak at $37.9 \mathrm{~min}), \mathrm{Q} 3(\mathrm{~m} / \mathrm{z}$ of 607.3 ; peak at $34.6 \mathrm{~min}), \mathrm{Q} 22$ $(\mathrm{m} / \mathrm{z}$ of 636.6 ; peak at $38.4 \mathrm{~min}) ;[\mathrm{M}+5 \mathrm{H}]^{5+}$ of Q4 $(\mathrm{m} / \mathrm{z}$ of 531.1 ; peak at $31.1 \mathrm{~min})$ and Q5 ( $/ \mathrm{m} / \mathrm{z}$ of 576.1 ; peak at $29.6 \mathrm{~min}) ;[\mathrm{M}+$ $6 \mathrm{H}]^{6+}$ of Q6 ( $\mathrm{m} / \mathrm{z}$ of 517.8; peak at $\left.28.4 \mathrm{~min}\right)$. All peptides elute between $5 \%$ and $\sim 35 \%$ acetonitrile with a maximal peak width of $\sim 40 \mathrm{~s}$, average peak width of $\sim 20 \mathrm{~s}$.

fragment ion $\mathrm{m} / \mathrm{z}$ following collision-induced dissociation. However, this sometimes requires a different instrument set-up (for example, analyte infusion) than is used for peptide analysis by LC-MS, and instrument sensitivity determined after positional optimization of the ionization needle used for infusion cannot readily be compared with instrument sensitivity for LC-MS analysis, if a different front-end configuration is used. A modified version of the Glu-fibrinogen peptide sequence (where the amino-terminal Glu was removed to decrease the potential of missed tryptic cleavage) was therefore incorporated into QCAL1 (Q8) to permit calibration post-fragmentation (data not shown) and assessment of instrument sensitivity using the same frontend configuration as is used for proteomics studies. The range of $\mathrm{m} / \mathrm{z}$ and charge states of the peptides included in QCAL1 (Q1-Q7) also permits optimization of the $\mathrm{m} / \mathrm{z}$-dependent nature of the collision voltage offset required to obtain high quality tandem MS spectra and thus the best possible peptide identification.

For quantification studies, assessing the linearity of signal detection of the instrument is also critical. Multiple copies of two variants of the Glu-fibrinogen derived peptide, where one $(\mathrm{Q} 9$, three copies) or two (Q10, six copies) additional glycine residues have been added to the peptide amino-terminus, were thus included in QCAL1 (Table 1). Analysis of these three peptides by LC-MS on a quadrupole-time of flight (Q-TOF) instrument demonstrated good linearity of signal, with Q8: Q9:Q10 being detected at a ratio of 1.0:3.1:6.2 $(n=4$, with S.D. of the ratios being 0.06 and 0.18 , respectively), calculated following integration of the extracted ion chromatogram for each of the peptides. This observation is consistent with the hypothesis that the additional glycine residues have little impact on peptide response factors in this system. The small percentage of the deamidated forms of these peptides did not compromise the linearity of response. MALDI-TOF (ABI Voyager instrument) analysis of the same peptides (Figure 1) yielded a ratio of 1.0:2.6:4.0 $(n=11$, with S.D. of the ratios being 0.28 and 0.53 , respectively). This may suggest either nonlinearity of response due to signal suppression of peptide ions in the unfractionated mixture, or that the additional glycine residues compromise ionization by MALDI to an extent not apparent by ESI. A similar effect was also seen following analysis on the Bruker Daltonics Ultraflex II TOF/TOF (data not shown) with ratios of 1.0:2.6:4.7 ( $n=6$, with S.D. of the ratios being 0.10 and 0.41 , respectively).

\section{Conclusions}

QCAL1 can be used for calibration and optimization of a number of instruments widely used in proteomics studies, as well as for testing and comparison during the development of new techniques and instruments for peptide analysis. This standard-available in substantial amounts with continuing availability due to the nature of its production-will enable the proteomics community to define in more detail the behavior of the instruments used in large-scale studies, thus facilitating long-term reproducibility in proteomics projects. Future iterations of QCAL could assess additional features used in proteomics analysis, for example peptide separation by strong-cation exchange chromatography, or alternative proteolytic agents such as AspN or GluC. Concatamers could also be designed to assess more extensively the performance of high-resolution instruments, or optimize different fragmentation techniques (collision-induced dissociation versus electron-transfer dissociation). The concept of "designer" proteins, such as QCAL, is thus readily extended from absolute quantification to new applications that could generate an effectively unlimited resource to ensure that all laboratories adopt common, carefully defined baseline calibration and assessment materials. 


\section{Acknowledgments}

The authors acknowledge support for this work by Biotechnology and Biological Sciences Research Council grants (BB/C007735/1) to S.J.G. and R.J.B.; C.E.E. is currently supported by a Royal Society Dorothy Hodgkin Fellowship. The authors thank Ms. Hannah Johnson for her assistance. They thank PolyQuant GmbH for gene design and construction.

\section{References}

1. Taylor, C. F.; Paton, N. W.; Lilley, K. S.; Binz, P. A.; Julian, R. K. Jr.; Jones, A. R.; Zhu, W.; Apweiler, R.; Aebersold, R.; Deutsch, E. W.; Dunn, M. J.; Heck, A. J.' Leitner, A. Macht, M. Mann, M.; Martens, L.; Neubert, T. A.; Patterson, S. D.; Ping, P.; Seymour, S. L.; Souda, P.; Tsugita, A.; Vandekerckhove, J.; Vondriska, T. M.; Whitelegge, J. P.; Wilkins, M. R.; Xenarios, I.; Yates, J. R. III; Hermjakob, H. The Minimum Information about a Proteomics Experiment (MIAPE). Nat. Biotechnol. 2007, 25, 887-893.

2. Beynon, R. J.; Doherty, M. K.; Pratt, J. M.; Gaskell, S. J. Multiplexed Absolute Quantification in Proteomics Using Artificial QCAT Proteins of Concatenated signature Peptides. Nat. Methods 2005, 2, 587-589.

3. Pratt, J. M.; Simpson, D. M.; Doherty, M. K.; Rivers, J.; Gaskell, S. J.; Beynon, R. J. Multiplexed Absolute Quantification for Proteomics Using Concatenated Signature Peptides Encoded by QconCAT Genes. Nat. Protoc. 2006, 1, 1029-1043

4. Rivers, J.; Simpson, D. M.; Robertson, D. H.; Gaskell, S. J.; Beynon, R. J. Absolute Multiplexed Quantitative Analysis of Protein Expression During Muscle Development Using QconCAT. Mol. Cell. Proteom. 2007, 6, 1416-1427.

5. Cottrell, J. S. Protein Identification by Peptide Mass Fingerprinting. Pept. Res. 1994, 7, 115-124.

6. Krause, E.; Wenschuh, H.; Jungblut, P. R. The Dominance of ArginineContaining Peptides in MALDI-Derived Tryptic Mass Fingerprints of Proteins. Anal. Chem. 1999, 71, 4160-4165.
7. Brancia, F. L.; Oliver, S. G.; Gaskell, S. J. Improved Matrix-Assisted Laser Desorption/Ionization Mass Spectrometric Analysis of Tryptic Hydrolysates of Proteins Following Guanidination of Lysine-Containing Peptides. Rapid Commun. Mass Spectrom. 2000, 14, 2070-2073.

8. Beardsley, R. L.; Karty, J. A.; Reilly, J. P. Enhancing the Intensities of Lysine-Terminated Tryptic Peptide Ions in Matrix-Assisted Laser Desorption/Ionization Mass Spectrometry. Rapid Commun. Mass Spectrom. 2000, 14, 2147-2153.

9. Hale, J. E.; Butler, J. P.; Knierman, M. D.; Becker, G. W. Increased Sensitivity of Tryptic Peptide Detection by MALDI-TOF Mass Spectrometry is Achieved by Conversion of Lysine to Homoarginine. Anal. Biochem. 2000, 287, 110-117.

10. Song, Y.; Schowen, R. L.; Borchardt, R. T.; Topp, E. M. Effect of 'Ph' on the Rate of Asparagine Deamidation in Polymeric Formulations: ' $\mathrm{pH}$ ' Rate Profile. J. Pharm. Sci. 2001, 90, 141-156.

11. Beausoleil, S. A.; Villen, J.; Gerber, S. A.; Rush, J.; Gygi, S. P. A Probability-Based Approach for High-Throughput Protein Phosphorylation Analysis and Site Localization. Nat. Biotechnol. 2006, 24, 12851292.

12. Olsen, J. V.; de Godoy, L. M.; Li, G.; Macek, B.; Mortensen, P.; Pesch, R. Makarov, A.; Lange, O.; Horning, S.; Mann, M. Parts per Million Mass Accuracy on an Orbitrap Mass Spectrometer via Lock Mass Injection into a C-Trap. Mol. Cell. Proteom. 2005, 4, 2010-2021.

13. Rivers, J.; McDonald, L.; Edwards, I. J.; Beynon, R. J. Asparagine Deamidation and the Role of Higher Order Protein Structure. J. Proteome Res. 2008, 7, 921-927.

14. Sun, W.; Wu, S.; Wang, X.; Zheng, D.; Gao, Y. A Systematical Analysis of Tryptic Peptide Identification with Reverse Phase Liquid Chromatography and Electrospray Ion Trap Mass Spectrometry. Genom. Proteom. Bioinformatics 2004, 2, 174-183.

15. Washburn, M. P.; Wolters, D.; Yates, J. R. III. Large-Scale Analysis of the Yeast Proteome by Multidimensional Protein Identification Technology. Nat. Biotechnol. 2001, 19, 242-247.

16. Krokhin, O. V. Sequence-Specific Retention Calculator. Algorithm for Peptide Retention Prediction in Ion-Pair RP-HPLC: Application to 300- and 100-A Pore Size C18 Sorbents. Anal. Chem. 2006, 78, 7785-7795. 